\title{
Mainstreaming LEADER Delivery of the RDR in Cumbria: An Interpretative Phenomenological Analysis
}

\author{
Ian Convery,* Ian Soane, Tom Dutson and Helen Shaw
}

\begin{abstract}
The European Union (EU) Rural Development Regulations (RDR) provide the blueprint for EU rural development policy. A major change with the 2007-20I3 funding period has been the decision to mainstream the LEADER programme as a cross-cutting axis for the local delivery of rural development. Delivery of the RDR in England (via the Rural Development Plan for England) has been devolved to the regions, and in the north-west there has been further sub-regional devolution. In Cumbria, where there is a history of successful LEADER programmes, a core group of stakeholders took the decision at an early stage to develop a proposal to deliver the whole of RDR Axes I and 3 funding via a mainstreamed LEADER approach. This article tracks the process of developing local action group proposals in Cumbria, and uses interpretive phenomenological analysis to explore the evolution of a local governance mechanism and provides a commentary on the tensions among mainstreaming, participation and innovation.
\end{abstract}

\section{Introduction}

$\mathrm{R}$ ural policy in the EU, as evidenced by the 2007-2013 Common Agricultural Policy (CAP) funding, is shifting further into environmental protection and rural development and further away from support for agricultural production. In addition, in order to develop integrated and multifunctional approaches to rural development, funds are being simplified, and alignments sought between measures, and across other funding streams. The broad aim of this policy shift is to achieve a sustainable future across environment, social and economic activities in the rural landscape. Accordingly, national and regional governments are being given flexibility in the selection and implementation of rural development measures, but are expected to use (that is, mainstream) the LEADER approach to provide a 'bottom-up innovative and participatory approach to secure at least 5 per cent of Rural Development Regulation (RDR) delivery' (Rural Development Plan for England (RDPE) 2007). 
In England RDR delivery is managed via the RDPE, which was finally approved by the EU in December 2007. Governance in England is further devolved to the regions, each developing a regional implementation plan (RIP). In the north-west the RIP has been developed by the North West Development Agency (NWDA), ${ }^{\mathrm{I}}$ in partnership with the Government Office North West, ${ }^{2}$ Natural England ${ }^{3}$ and the Forestry Commission. ${ }^{4}$ Additionally, there is further devolution to the sub-regional level in the north-west, and the NWDA has engaged with sub-regional partners in Cumbria, Lancashire, Merseyside, Greater Manchester and Cheshire to develop sub-regional implementation plans (SRIPs) (NWDA 2007). In Cumbria, the former success of LEADER has been highlighted in the Cumbria RIP, and was suggested as a major mechanism for dispersal of Axes I and 3 funds. The Cumbria SRIP (2007) states: 'Cumbria has a very strong track record in delivering LEADER programmes'. During the period 2000-2006 it had two LEADER+ local action groups (LAGs); 'Fells and Dales and a part of the North Pennines LAG, and has experience of LEADER since I996'. (Figure 1)

This article, which is developed from research commissioned by the International Centre for the Uplands, presents a novel real-time analysis of the tensions between developing a governance system that meets mainstream requirements while retaining the innovative and participatory characteristics of LEADER, drawing on relevant theories such as adaptive management and participation. We do this using an interpretive phenomenological analysis (IPA) approach, which is particularly well suited to capturing and assigning the meanings that participants assign to their experiences. We follow the early stages of developing the SRIP for Cumbria, focusing on the development of two LAGs: Fells and Dales (FD), and Solway Border and Eden (SBE) (with particular emphasis on the SBE grouping as the new LAG). We focus on Cumbria because it has a track record of delivering LEADER programmes and also because the NWDA took a bold step in devolving power at an early stage to the sub-regions, which is in some contrast to the process from other English RDAs. It follows that one of the key questions we address in this article is, how well has this approach worked? The article thus considers the LEADER approach to rural development and how this fits within a Cumbrian context, in order to meet the stated RDPE aims of integration and sustainability. Firstly, however, some background information about LEADER and the RDR is presented.

\section{Background to LEADER}

LEADER is an area-based participatory approach to rural development. LEADER was initially piloted in selected EU regions in I99I-I992 and has since gone through two iterations: LEADER II (I993-I999) and LEADER+ (2000-2006). Woods (2005) describes LEADER as a shift in the nature of rural development, with a focus on capacity building and valuing local resources. MacKinnon (2002) highlights the role of LEADER in pioneering participation and bottom-up development. Scott (2002) states that LEADER embodies the essential elements of the bottom-up approach to rural development. However, despite the bottom-up ethos of LEADER, the programme has always comprised both top-down and bottom-up elements (Bryden 2006). Cazorla-Montero et al. (2005, p. 70I) also note the apparent paradox of LEADER, stating that from the EU Commission, 'planning is promoted at the lowest 

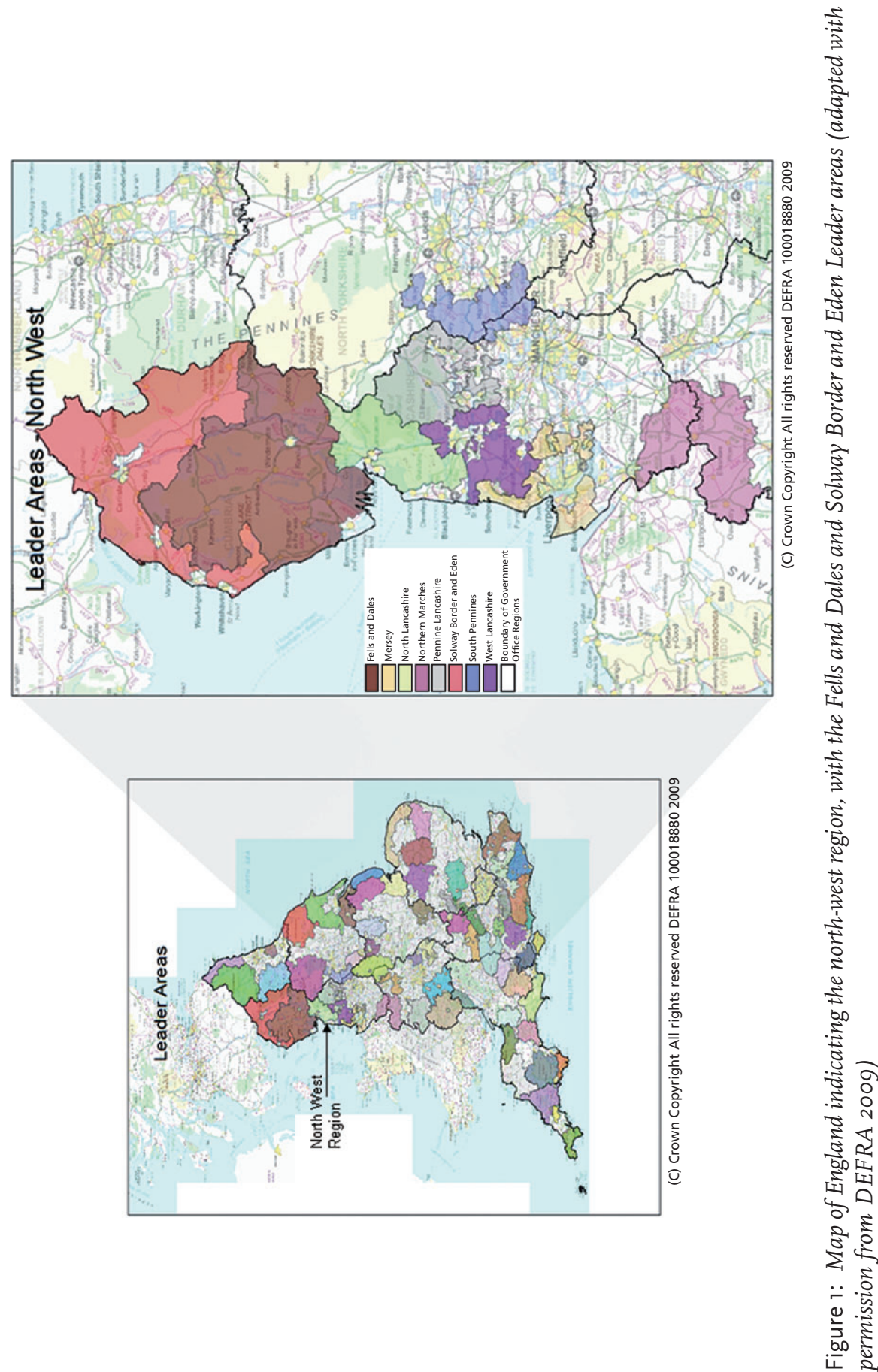

(C) 2010 The Authors. Sociologia Ruralis (c) 2010 European Society for Rural Sociology. Sociologia Ruralis, Vol 50, Number 4, October 2010 
local level ... it presupposes planning simultaneously from above and below'. The LEADER process is structured by a set of objectives that have been proposed and negotiated by member states - the top-down element. At the local level a group of stakeholders (the LAG) may make the final choice of which goals and elements of the programme they consider relevant and deliverable in their local area and have the flexibility to select the method of achieving those goals. MacKinnon (2002) highlights this specificity and states that LEADER groups in Northern Ireland have supported community development in a number of ways, including the employment of extension networks, support for tourism, training and marketing support and community appraisal projects. Scott (2002) cites the importance of LEADER in building relationships and brokering connections in the local economy, creating capacity to collaborate and co-ordinate across public, private and community sectors.

Under previous LEADER programmes, innovation and sharing experiences were major aims, and Ray (2000) describes the LEADER programme as a 'laboratory for rural development ... each LEADER group to search for innovative ideas ... community-driven, territorially focused development, values local resources, physical and human'. Given this emphasis on experimentation, it is perhaps unsurprisingly that, while the LEADER programme has been a success in many respects, there have also been a number of problems and criticisms. For example, Barke and Newton (I997, p. 338) contest the stated endogenous nature of LEADER, arguing instead that in Andalusia LEADER has developed projects that are not 'necessarily truly local in origin and which seem unlikely to have led to any fundamental change in the wider processes of social organisation'. Perez (2000, p. 206), though generally supportive of 'the significant impact of LEADER in Spain', cautions against the fragmentation of LAGs into narrow interest lobbies, each trying to use LEADER as an instrument of power. Bruckmeier (2000) argues that, in Germany, LEADER has often been a conservative force moderating more radical rural ideas. Storey (I999) discusses concerns regarding the extent of local participation in LEADER schemes in Ireland. Similarly, Scott (2004) discusses the need to extend the partnership process to include the most marginalised members of the community, and states that inclusive social capital formation remains a key challenge for LEADER partnerships in Northern Ireland. Vidal (2009) summaries the criticisms of LEADER as being about the nature and success of local partnerships; defining innovation in practice; the notion of community involvement; and the vagueness of LEADER aims and objectives.

Despite such criticisms, LEADER is generally viewed as a successful EU rural development initiative (Buller 2000; Perez 2000; MacKinnon 2002; Austrian Institute for Regional Studies and Spatial Planning 2004; Scott 2004; Cazorla-Montero et al. 2005; Vidal 2009). Vidal (2009) states that LEADER has achieved much since I99I, particularly in relation to less tangible outcomes that are more difficult to measure. Cazorla-Montero et al. (2005) state that LEADER can be considered the last great step in the evolution of rural development in the EU. LEADER been successful in the past by balancing sectoral interests at local level (horizontal integration) with the requirement for integration of environmental objectives through all EU policies (vertical integration). However, the current LEADER programme (2007-2013) differs from previous incarnations in that it effectively represents a mainstreaming of the LEADER approach across the RDR rather that a discrete LEADER programme. As 
McEvoy et al. (2008) note, the concept of mainstreaming gained prominence during the World Summit on Sustainable Development (Johannesburg 2002), initially in connection with the integration of climate change considerations into development assistance. More recently it has been applied to wider policy contexts, that is, strategies for adaptation are being embedded within existing sectoral policies and institutional frameworks. In EU terminology, 'mainstreaming' is used to refer to a process of integration in the wider policies of the EU, so that an issue or innovation it is fully taken into account in all EU polices. Thus, mainstreaming LEADER describes the transfer of part or all of the LEADER approach to mainstream rural development programmes, whether co-financed or nationally financed (Courades 2004).

\section{The RDR 2007-2013}

The RDR was first introduced as Pillar II of the CAP in the 2000-2006 financial perspective. In June 2005 the European Agricultural Fund for Rural Development (EAFRD) replaced the European Agricultural Guidance and Guarantee Fund as the primary EU mechanism for funding rural development for the period 2007-2013. ${ }^{5}$ For the first time the RDR funding will be simplified to come from one budget and thus allow the EAFRD to align fully with the Lisbon Strategy and the Gothenberg sustainability goals (Bryden 2006). Under this new arrangement, funding is split across three axes, with a fourth cross-cutting axis under which the LEADER approach will be used to implement the measures (which set out activities eligible for funding) under some of the other axes. The RDR allows, through flexibility in the percentages of funding allocated to Axes I to 3, a 'national view' to emerge and in the RDPE, the government has emphasised environmental issues by allocating the maximum percentage of funds to Axis 2:

- Axis I (Improving the competitiveness of the farming and forestry sectors) will receive Io per cent of programme funding and (under the RDPE) will be managed by the Regional Development Agencies ${ }^{6}$

- Axis II (Improving the environment and countryside) will be managed by Natural England and the Forestry Commission and will receive 80 per cent of the funding allocation. Most of the present agri-environment schemes - the England Woodland Grant Scheme, the Farm Woodland Premium, Organic Farming, Countryside Stewardship, Environmentally Sensitive Area payments, Entry Level Scheme and Higher Level Stewardship - will be bundled up and repackaged in a new Environmental Land Management Fund. It is understood that Natural England and the Forestry Commission will not adopt the LEADER method to implement Axis 2

- Axis III (Rural quality of life and diversification of the rural economy) will receive Io per cent of programme funding and will be managed by the regional development agencies

- Axis IV: a cross-cutting principle that brings a minimum of 5 per cent of the programme through local delivery (see below).

Clearly, an important development in the 2007-20I3 RDR is the stated focus on participation and local innovation via the mainstreaming of the LEADER approach. 
Community Strategic guidelines (EC no. I698/2005) state that LEADER, as Axis 4, 'introduces possibilities for innovative governance through locally based, bottom-up approaches to rural development'. RDR guidelines stress the relevance of LEADER to Axis 3, but also the opportunity to utilise LEADER as a mechanism for horizontal integration; improving governance and mobilising endogenous development. At the regional level this situation is further complicated by the requirement for a strategic fit across programmes, which figures prominently in the north-west RIP (NWDA 2007).

Despite future uncertainties (including the issue of modulation and the future balance between the CAP Pillars vis-à-vis market support and rural development) the RDR provides an increasingly important mechanism for rural development by combining innovation in rural diversification and environmental protection. The successful implementation of the objectives of the 2007-20I3 RDR will therefore require focus on the integration of bottom-up approaches with top-down programme aims, delivered through a mainstreamed LEADER approach.

\section{Methods}

IPA originates from social psychology but is of increasing interest to social scientists from other disciplines, particularly sociology and human geography. IPA is an inductive approach that is ideally suited to the development of complex and interrelated themes (Jordan et al. 2007). As Reid et al. (2005) indicate, it does not test hypotheses but aims to capture and explore the meanings that participants assign to their experiences (see Smith and Osborne 2003 for a full account of IPA). LEADER programmes have been subject to various methods of evaluation, and in this research we have attempted to use a new approach and to follow in real-time the development of a LEADER governance strategy. In doing so we provide the perspectives of participants involved in the process. We wanted to let the data speak for themselves and for participants to themselves identify how they saw their role and that of others.

It is not the aim of IPA to achieve a representative sample in terms of either population or probability (Darker et al. 2007). Respondents were recruited purposefully to reflect their expertise in the area of study, including representatives of all the agencies listed in Table 1, together with the NWDA, the National Farmers Union, Longtown Market Towns Initiative and Carlisle City Council. In total, I7 semistructured interviews were completed (which is at the high end of IPA studies). The interviews were transcribed and anonymised using interview codes. While IPA is

Table 1: The sub-regional implementation plans writing group

\begin{tabular}{ll}
\hline Cumbria County Council & Fells and Dales LEADER+ programme \\
Cumbria Vision & North Pennines LEADER+ programme \\
District Councils (represented by Eden & Natural England \\
District Council) & \\
Cumbria Rural Enterprise Agency & Forestry Commission Cumbria Woodlands \\
International Centre of the Uplands & \\
\hline
\end{tabular}


strongly idiographic it is also flexible enough to allow unanticipated topics or themes to emerge during data analysis (Smith 2004). A series of data clinics was held, during which each transcript was analysed individually before a final cross-case analysis of the dataset was undertaken. The process of documenting themes in this way transforms initial comments from crude analysis to a high level of conceptualisation (Tomura 2009). This process led to a range of issues for consideration:

- The sub-regional RDR development process

- LAG geography and development

- Integration (particularly across Axis 2).

The following sections develop these issues further and link substantive interview material alongside relevant policy and academic literature to track the process of RDPE development in Cumbria and its relevance to the processes of mainstreaming, innovation and the competing drivers of legitimacy, representation and expertise within the participatory approach.

\section{The sub-regional RDR development process}

There's something really peculiar happened in England, the civil servants in [Department of Environment, Food and Rural Affairs] DEFRA a year or so ago decided that there wasn't going to be a LEADER programme in England.... They said it's not a programme any more, the technique is now being mainstreamed. (IoI, March 2007)

In Cumbria a core group of stakeholders took the decision at an early stage to develop a proposal to deliver the whole of Axes I and 3 funding via a mainstreamed LEADER approach. The work to develop a strong case for mainstreamed LEADER (and capacity building to support this process) preceded formal NWDA invitations to develop LEADER groups with a focus on presenting a highly organised and united plan to the NWDA. The SRIP was developed via a writing group comprising a number of national and regional agencies.

This core group had previously been involved in stakeholder consultations run by DEFRA on the RDPE. The group took a strong lead from the Cumbria County Council European Office and the then FD LAG manager, and the subsequent development process was facilitated by a series of events and discussion groups. One of our initial questions to respondents was simply 'why this group?' Responses indicate that the mandate of this group was unclear to many respondents, and despite a high level of trust and respect for the expertise and knowledge of the individuals involved, there were concerns about the representativeness of the core group. Some respondents suggested that the process had been pushed through without sufficient consultation:

We've been dictated by Fells and Dales and the way that's worked. (III, May 2007)

I think it's probably as much personality as anything else ... I suspect that's why Cumbria's got what it's got with regard to RDPE. Yes there is a momentum to be kept, but at the same time LAG members in Cumbria, they want to be involved. (Io4, March 2007)

Some respondents voiced concerns regarding the organisational structure (and hence the legitimacy) of the proposed RDPE in Cumbria: 
What you've got is an unholy alliance between the County Council as the accountable body, the [NWDA] and the LAGs down here, and somehow that's all got to fit together. (Io3, May 2007)

Others were sceptical about NWDA's commitment to local accountability in rural development:

They're [NWDA] not terribly interested in rural policy. NWDA have said in terms of rural policy they're interested in iconic projects ... they're not interested in small-scale schemes. So LEADER, I think, is probably not on their radar, because it's all small scale. (III, July 2007)

Other respondents were very positive about the participatory approach of the FD LAG in its previous incarnations and its ability to provide local solutions. This led to an appreciation of its leadership with reference to the new RDR:

[FD has been successful because] local people have been encouraged to come forward with project ideas. They have had help to prepare project proposals and identify possibilities to put forward. It has been a highly proactive approach. (II6, December 2007)

Fells and Dales clearly had its successes ... I'd say we've been very lucky with X [from FD]. (Io2, December 2007)

Several respondents involved in both the writing group and LAG formation groups expressed doubts about their understanding of the LEADER process and the new RDR, and felt that they were reliant on the expertise of Cumbria County Council officers to provide information and guidance. Scott (2004) notes that the unequal availability of information among the partners was a common criticism among LEADER groups in Northern Ireland. In Cumbria, this arguably created a culture of accepting rather than challenging both the governance structures and the emerging shape of the sub-regional programme:

I've not been involved in LEADER in Cumbria for very long ... I'm coming in on the tail end of it. I've not seen from the start of the process and how it's developed and everything. (Io6, April 2007)

Not really [any involvement with LEADER in the past] ... pretty nil for me. (Io8, April 2007)

I haven't got the history in terms of my direct involvement with LEADER. (Io8, April 2007)

A further issue with the SRIP development process concerned the selection of RDR measures. In Cumbria the requirement to deliver a SRIP to the NWDA led to difficulties in timetabling LAG development. In particular, the writing of the SRIP predated, therefore precluded, LAG involvement in the selection of measures. Perhaps unsurprisingly, the preselection of measures was voiced as an issue, both in the Cumbrian writing group meetings and in the interview research. Nevertheless, this concern demonstrated a real understanding that mainstreaming would require both a match with national or regional top-down measures and an ability to tackle local problems using locally evolved methods. Respondents were particularly concerned by a perceived lack of opportunity and flexibility for the LAGs to make their own thematic decisions and the need to maintain a bottom-up approach:

[T]here's going to be a real tension coming up now between the projects that have come up from the bottom and the measures that have come down from the top, and if we're not 
careful they are going to completely miss each other. Somehow we've got to convert all these ideas that have come from the grassroots into the measures ... it does make it complicated ... its measures that are going to win, because they're written in stone. (II4, July 2007)

[T] here's going to be a lot of frustration from people who've been involved [in LEADER programmes in the past] if they transfer to the new LAGs and they're looking to do similar types of projects because that won't be possible [because of the changing measures]. (Io8, April 2007)

However, others took a more pragmatic view that was more optimistic concerning the ability to achieve vertical integration:

I don't think we have a lot of choice about them ... I mean measures are given to us ... I think some measures were de-selected [but] I'm quite happy that the measures that have been selected are sufficient to allow us to see a fit between what we would like to develop and the measures that are there. (III5, July 2007)

Despite the ethos of LEADER as a bottom-up method, as indicated earlier it has historically combined this with a level of top-down control in the overall planning, which Scott (2002) argues can limit opportunities for LAGs to develop integrated approaches to rural development. While a degree of top-down control may be important from an overall programme delivery perspective, Bryden (2006) cautions that 'the more that themes and actions are closely defined at the centre, the less freedom there is for LAGs to innovate'. Some respondents voiced concerns that the new mainstreamed LEADER would be much more restrictive than previous incarnations:

There doesn't seem to be the same flexibility in the current programme to integrate social and economic in this programme as there was in previous ones. Simply because the measures are a lot more focused on agricultural and forestry competitiveness and very little emphasis on developing the social elements of the programme. (Io8, May 2007)

[The] programme is not necessarily about local needs, much more about top-down prescription from Brussels, from [the] UK government, from NWDA. I think the amount of flexibility is very much less than LEADER has previously enjoyed. The operation of a LAG is not going to be the same as has happened previously ... you want to go bottom-up but you've got top-down priorities and boxes that need to be ticked so.... It's [also] about managing expectations at the local level, making sure that you give them a local voice but also saying, 'yeah, that would be brilliant but [the new programme] will come with a whole host of expectations that you will have to counteract time and again'. (Io3, May 2007)

Respondents were also concerned that, with the mainstreamed approach, the mandate for project approval may shift from the LAG to NWDA:

It's a new programme, let's be honest about it, mainstreaming always comes with pain, it's not LEADER 3 or LEADER ++ or whatever you want to call it ... most of Axis I is bring delivered through something else, not through the LAGs. Obviously the proposals for Cumbria include a series of measures and the writing group has done some work with regard to what that might mean and what that might look like ... it feels a bit contrary to the LEADER approach, it almost directional. Yes its strength [mainstreamed LEADER] is that there'll be a certain amount of capacity and a certain amount of understanding of what all of that means and all that but ... if you have to go back time and again to say, 'well, actually, this is different, this is much more economically focused, it's much more constrained through 
other linkages to other strategies and plans and such like'... [There needs to be a] a matching of expectations to what can actually be delivered so that people at [the] grassroots don't become disillusioned because the signals are given for grassroots projects but the measures or the funding simply aren't there to support them. (Io4, March 2007)

The measures do then start to restrict what you can do ... when you look at the prescription of the measures, what you can actually do. (Io3, March 2007)

Well, I think the way the LEADER methods has worked in the past is that applications genuinely come, even if LEADER help work them up, from businesses and communities on the ground, in the sticks. And then the LEADER staff help them to work it up then it goes to the LAG for approval, and that's it. Once the LAG approves it the money goes through all the due process back out to the customer. Now, we've got this huge complication ... North West Development Agency may well think, 'Okay, Io of these [projects] are good, these are the ones we're going to run with', which immediately restricts opportunity coming up from the bottom, but they may want to be even more prescriptive and say ... I don't know, they may want the applications to come straight to them rather than the LAG. (II4, July 2007)

Unfortunately, respondents' concerns were well founded, with the mandate indeed effectively shifting from the LAG to the NWDA. This is well illustrated by two headlines from the Cumberland News (the county newspaper). The first, from 2008, is 'Rural Cumbria has been starved of cash by political wrangles' and the second, from 2009, is 'Cumbrian farmers still waiting for cash from $£^{\mathrm{I}} 6$ million grants pot'.

In the 2008 article Burdett (2008) writes how

Rural Cumbria has been starved of funding for two years because of political wrangling ... it has been delayed by political disagreements and bureaucracy ... it is still unclear what kind of projects the money will support when it is delivered by the NWDA.

One year on and the situation had not improved. Burdett (2009) writes, 'the process of releasing funds has proved unwieldy and long-winded as every application to either group has to also go through the Northwest Regional Development Agency'. She adds, 'it took the NWDA six weeks to rubber stamp a LAG-approved application for a bio-diesel minibus in Brampton. The total application process took five months'. It is likely that the 36-page application form the NWDA initially devised was not conducive to rapid applications and assessment.

The preselection of measures was viewed by many as a cause of reduced flexibility with the new LEADER. However, this preselection of measures is not unique to Cumbria and is linked to the timing of overall programme implementation. There is an interesting paradox with the current situation in Cumbria; in choosing to mainstream LEADER, it has perhaps been left with less flexibility than other areas that have opted for a regional implementation plan for most of the funds, but it has thus maintained flexibility for the proportion of funds to be delivered by LEADER. However, it is also possible that other regions may give the LAGs very little option in the selection of measures. For example, in the south-east region LEADER LAG applications are partially evaluated on the fit of the proposed action plans and LAG projects to regionally selected measures. Bryden (2006) observes that each of the preceding three LEADER programmes has become increasingly difficult to develop due to bureaucratic pressures and this factor must be taken into account in future funding rounds. The overall picture that emerges from the above discussions is one 
of an emerging governance group that comprised a range of individuals, all of whom were very uncertain of their prospects of being able to exert real power and who were reliant on a few experts to develop their knowledge of issues and of complex bureaucratic regulations.

We would argue, however, that the knowledge of the whole group is necessary to produce local knowledge and that this must be allowed to develop and evolve alongside the LAG. As Ostrom (2005) notes, all policies ought to be viewed as ongoing learning experiments that need to be monitored, evaluated and adapted over time. How might this be best achieved? Folke et al. (2005) argues that in order to address complex interactions and to manage uncertainty and periods of change, governance approaches that are adaptive have much to offer. Such approaches are based on concepts of collaboration and flexible and learning-based issue management across a range of different scales (Olsson et al. 2006; Olsson and Folke 2004). This would necessarily require a higher level of social capacity than is present in the current LAG structures.

\section{LAG geography and development}

In July 2008 the NWDA accepted LAG proposals by both the FD and the SBE groupings. This was clearly good news for those concerned, but the geographical area defining the new LAGs was not without controversy. The development of proposals for LAG geography (Figure 2) appears have been driven by Cumbria County Council and the existing FD LAG. Many interview respondents felt that decisions on LAG areas was presented at an early stage to the wider stakeholder network as a fait accompli and rested heavily on maintaining the existing FD LAG structure and boundaries. However, LAG geography was constrained by a number of factors. Firstly, the size of LAG needed to be within community guidelines (between 5000 and 150,000 people), meaning that a Cumbria-wide LAG would have been rejected as too large, and secondly, there was a feeling that the development of a large number of small LAGs would reduce LAG funding to the point where it was too small to accomplish worthwhile project outcomes. There was also an inference that the NWDA would reject a large number of separate LAG applications. As a respondent noted:

I think it's fair to say it [having more than two LAGs] would have frightened away NWDA to the extent that they would have run away from us ... we are where we are because of concerns about keeping the NWDA onside for this. (III, July 2007)

The SBE Local Development Strategy (Solway, Border and Eden Local Action Group, 2008) puts forward an argument for LAG geography as follows:

[The SBE] area contains most of the lowland agriculture in Cumbria. It has suffered from considerable structural problems in recent years, but also represents an area of considerable economic and social opportunity. It has a number of key market towns, considerable underrealised tourism potential and a strong network of local organisations. It is an ideal area in which to deliver rural development using the LEADER approach. The proposed LAG area was defined by partners following an extensive examination of options. The process used to define the LAG areas was to use the 'joint character areas' identified by Natural England as the building blocks. These joint character areas were then combined on the basis of local knowledge and understanding of common heritage, culture and connections between the 


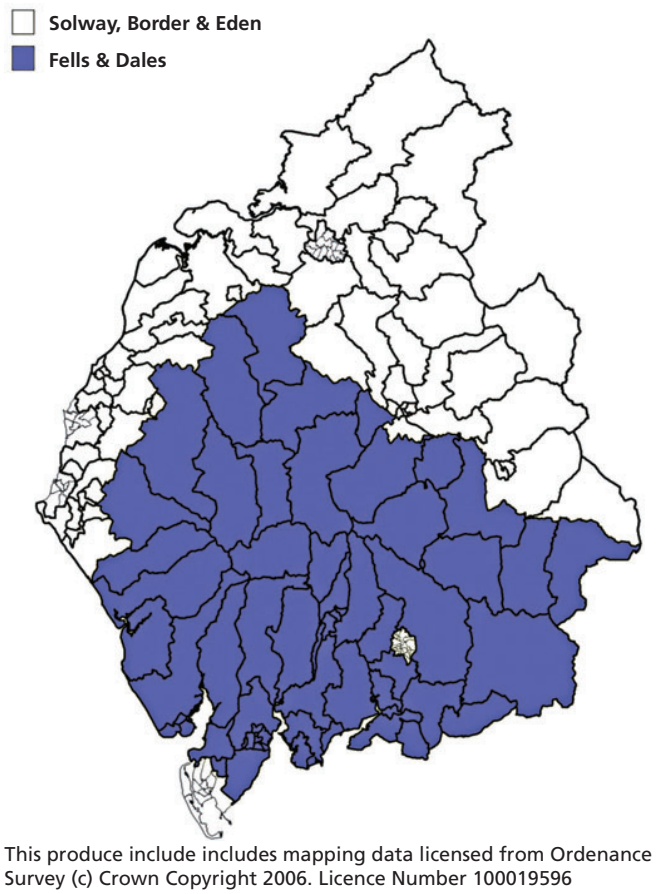

Figure 2: Map of proposed LAG areas (Solway, Border and Eden Local Action Group, 2008)(adapted with permission from DEFRA 2009)

areas. Therefore, the proposed SBE LAG is based on a detailed process that has been supported by a wide range of partners.

The total population of the area is 157,988 . Although this is slightly over the recommended population limit of $\mathrm{I50}, 000$, the LEADER regulations note that 'properly justified exceptions may be accepted'. In this case, partners believe that the area has a natural coherence and sense of distinct character which has been the basis of development work for over I8 months. To arbitrarily disrupt the coherence of the area was felt to be unhelpful, so partners would like to make a case for permitting this slight (5.3 per cent) increase in population.

Devising a new governance structure to deliver the LEADER approach faced the problem of meeting legal population requirements to achieve LAG status while adequately representing a community from whom community representatives could be identified and invited to participate in the development of the rural development plan. Respondents, while accepting the logic for the continuation of the FD LAG (albeit slightly enlarged), voiced strong feelings that the proposed SBE LAG was 'made up of all the rest of Cumbria that was not the FD LAG'. Some expressed concerns that the experience of the former LEADER+ North Pennines LAG was being lost or sidelined by incorporation into the larger, predominantly lowland SBE LAG. Although a case has been argued for cohesiveness of the SBE LAG in terms of farm 
type and character area, there has also been much concern expressed over a lack of cohesive identity for the SBE LAG:

I've got concerns about how what we're doing relates to communities of place and I don't think it bears any relationship to communities of place. I think it bears some relationship to landscape characterisation, but I've been in Cumbria for 30 years and I've been working in terms of community identity, on and off for about that length of time, and this is a completely new map to me. It doesn't even relate to Cumberland and Westmorland.... When the initial thinking was taking place it wasn't in the context of ideas of community identity, it was as if 'We'd like to have one for Cumbria? We can't have one for Cumbria, therefore we'll have to break it into two'. I think that's as far as the thinking went. So we're going to break it into two, the A66 seems as good a place as any, we'll just ... so there it is. (III, May 2007)

I think if we don't address it [LAG selection] properly within the writing group and within the written information that we send to NWDA you could drive a coach and horses through it. (II5, July 2007)

It's [SBE LAG] the bits that didn't exist. (Io3, May 2007)

It's not an easily cohesive area to champion really. (Io8, May 2007)

There is little evidence at this stage to judge the adequacy of the LAG area selection to desired programme outcomes. Certainly there are other areas of the UK where there was more freedom for innovative LAG development, for example, the South West RDA led a series of capacity-building workshops which led to 35 LAG expressions of interest. It could be argued, however, that this type of situation may be equally undesirable as it places unrealistic pressure on funds and may lead to disappointment and the possible fracture of community aspirations at the early stage. Furthermore, the large number of LAG applications in some regions may in part have been due to a lack of time to build consensus between the capacity-building and application stage. Given this, it could be argued that in Cumbria the continuation of the successful FD LAG and the strongly driven focus on two LAGs may well prove to be an important unifying feature. However, given the worries expressed by some over the unsuitability of the SBE LAG, the proposal (SBE LAG SBES 2008) to subdivide the LAG into West Cumbria, Eden and Carlisle and Borders sub-LAGs may prove vital to overcoming the considerable difference and geographical distance that may act as a barrier to the LEADER objective of developing projects through community commonalities. As one respondent noted:

One of the things that we haven't at all discussed is mechanisms of operation and practicalities of drawing people from the far west of Cumbria and Brough and Longtown. There are some serious issues to address there, these are huge areas. (Io4, March 2007)

The decisions about LAG geography demonstrate how a genuinely bottom-up policy initiative to deliver as much as possible of the RDR through the LEADER mechanism has resulted in one LAG where the concern for legitimacy has been perceived by some as taking priority at the expense of the representativeness of its participants. As always, there is a difficult balance to be struck between top-down and bottom-up approaches. While community participation is invariably seen as positive and is deemed necessary for empowerment and increasing social inclusion, as Smith et al. 
(I999) note, this can frequently be difficult to achieve as community members may be reluctant to assume responsibility and often look to outside agencies for leadership.

\section{Integration}

Within the RDR integration is required in the application of RDR measures and priorities. Commission Regulation (EC) no. 8I7/2004 calls for the "management of integrated rural development strategies by local partners and the requirement to demonstrate 'how the integrated approach has been applied'. This approach aims to join up horizontal sectoral interests via co-operation in delivery. It also aims to take account of national and global external impacts and interests by ensuring complementarity with other relevant policies and vertical funding mechanisms.

Integration has long been a stated aim of the LEADER approach, and within the EU the I996 Cork Declaration (EU Rural Development Conference; Rural Europe Future Perspectives) includes the need for an integrated approach and a for rural development policy that is multidisciplinary in concept, and multi-sectoral in application as part of its Io-point proposal. There is also clear UK governmental guidance on recognising and integrating rural issues across government departments and policy under the terms of rural proofing, initiated as part of the 2000 Rural White Paper.

The need for integration has also been recognised at the sub-regional level, for example, the Cumbrian SRIP (2007) emphasises 'co-operation' as an important feature, 'building on the very positive experiences of the previous LEADER+ programmes'. However, the SBE LAG development strategy (SBE LAG, SBES 2008, p. 39) notes that while integration between 'Axes I and 3 can be achieved through the LAG taking a strategic view of projects ... integration with Axis 2 will require a more proactive approach'. There is a expectation that integration will develop at a project level, through a 'living landscape' approach where

the involvement of Natural England and the Forestry Commission in LAG meetings will enable initiatives in particular locations to be integrated between axes; for example, targeted support to local tourism initiatives, or to new business creation opportunities, could be planned to complement Environmental Stewardship and England Woodland Grant support ... in a particular village or valley. (SBE LAG, SBES 2008, p. 39)

However, it is also important to recognise the reality of funding disparity within the RDR, with 80 per cent going to Axis 2. Unsurprisingly, the integration of Axis 2 with Axes I and 3 formed a major topic of discussion with respondents. In particular, there were concerns regarding the mechanisms for facilitating integration with Axes 2 under current arrangements (both financial and regulatory) and a perceived unwillingness to engage on the part of Natural England. At the same time there was recognition that this was probably linked to the early stages of policy development in Natural England (which was established in 2006). There was also an awareness of the value of existing forestry schemes due in greater part to the existing local partnership between the Forestry Commission and Cumbria Woodlands in the delivery of the successful forest futures project. In terms of horizontal integration, respondents focused on the issues of Axis 2: 
The most difficult thing is going to be integrating with Axis 2 where there are no mechanisms, there's certainly no money out of Axis 2. But it's not like the door's closed completely and there is a willingness in both the Natural England local players and Forestry Commission local players involved in the writing group and this surrounding area to explore those options. If they get curtailed by their national offices then it might be difficult, but locally and regionally there is a willingness to do that, which I think is an important element. (Io4, March 2007)

How is that programme is going to work with Natural England and the Forestry Commission's delivery of Axis 2? I think that's the question where the integration needs more work. Until we know what their programme's going to be and how they're going to operate and ... but clearly there needs to be a great deal of understanding between the two programmes and some overlap in terms of personnel. So [it requires] somebody from Natural England or Forestry Commission on the LAGs to get that integration and synergy. (Io8, May 2007)

The message that seems to be getting back from Natural England and Forestry Commission is that [integration] is not going to be happening ... that said, there has been a commitment from Natural England, Forestry Commission, to be involved in the LAG and be involved in that process. (Io5, April 2007)

Somehow we have to try over a period of time to tease Axis 2 out into being much more mainstream. We actually want to make sure that Axes I and 3 complement what Axis 2 is doing, but when one of the parties doesn't bring cash to the table it's much more difficult to see how the rationale is going to apply. The pressure effectively all goes the opposite way; it's Axis 2 starting to influence how Axis I is spent, not Axis I influencing how Axis 2 is spent. I don't have an answer other than 'Keep talking'. (Io3, May 2007)

There are so many vested interests, it is very difficult to 'integrate' across the various axes as agencies have their own agendas. (II6, December 2007)

While a strategic, agency-focused approach to integration across Axes I-3 was seen by most respondents as difficult and extremely challenging, there was a feeling that integration would develop on a project by project basis:

I think at strategic level it needs to be that willingness to look across the board but I think it's [integration with Axis 2] going to be on a probably on a project basis. We are very keen to be as integrated as possible. But we have to operate within the confines of a national scheme, so that does present us with certain issues ... it's a matter of alignment rather than letting them make the decisions about where money is allocated. (Io7, May 2007)

In terms of vertical integration, respondents were also very much aware of the need to integrate with a range of regional, national and European policies:

I mean ... there's integration, isn't there, in a number of ways? There's integration within the programme itself across the axes. Then there's the integration in the wider regeneration in Cumbria. How is it going to integrate with the work of Cumbria Vision? The regional rural delivery framework? (Io8, May 2007)

I think external integration, which is connecting it to the other policies and programmes that have an impact on rural Cumbria, [is a] very strong driver behind the [LEADER] programme this time round, as opposed to how, say, LEADER has been developed in the past. One of them [the drivers] is to connect with the other regional development agency policies that have an impact on rural programmes, particularly the new rural delivery framework and all those associated programmes that come with it and whatever follows the market town initiatives, I think all of those are important. They are regional programmes with a bit of 
national impetus behind them and we need to connect with them. And then on the European side it's very important [to] connect with the other main structural fund programmes. (Io2, March 2007)

The RDR emphasis on integration raises significant issues for the devolved structure of the RDPE, particularly in the north-west, where the sub-regional structure provides additional challenges. However, it is important to note that integration is not an end in itself but is a simply a mechanism to develop a policy system that can deliver sustainable environments, communities and economies. Interview data revealed concerns about the mechanisms for integration with Axis 2, but also an expectation that integration would develop, based around specific local partnerships. This shared aspiration has the potential to provide a significant mechanism within the evolving LAG structures. It could build on the relatively strong history of local partnerships in Cumbria through projects such as Cumbria Woodlands Forest Futures, which involved collaboration between a range of agencies, including the Forestry Commission, NWDA, Cumbria County Council and (what was then) English Nature (Forest Research 2005).

\section{Discussion}

The RDR was first introduced as Pillar II of the CAP in the 2000-2006 financial perspective. The LEADER approach, incorporated into the current 2007-20I3 RDR, evolved through a separate, but aligned pathway of EU structural funds and is focused on the widely accepted requirement to shift to devolved and localised participatory governance structures. Earlier we discussed how the NWDA had taken a bold step in devolving power at an early stage to the sub-regions and how this was in some contrast to the process in other English RDAs. Most of them organised regional seminars and discussions to promote the RDR and the LEADER approach, and have therefore been directly engaged in capacity building through exercises such as drafting regional plans prior to invitations for LAG expressions of interest. In this article we have presented a detailed case study of how the NWDA approach has fared.

Before discussing this, however, it is important to recognise the dynamic role of the researcher in both generating and analysing the data. This article is based on a limited set of narratives and a specific interpretation of the data. Indeed, a fundamental principle of IPA is that there are potentially multiple accounts of the data. This does not mean that any one account is incorrect but it does mean that each interaction between researchers and participants is unique (Jordan et al. 2007). Nevertheless, the interpretation of the data given here suggests that the process of developing FD and SBE LAG submissions for the new RDPE in Cumbria was a complex balancing act: seeking 'engagement and participation' regarding LAG development, but at the same time 'providing leadership' and mainstreaming 'new' LEADER. In recording this process, we shed light on the governance problems associated with mainstreaming local policy delivery while maintaining local identity and innovation and the difficulties of securing empowering, capacity-building and representative participation. Cumbria partners had to evolve two new geographically based governance structures for rural delivery that recognised the powerful role of NWDA, maintained the 
innovative ethos of 'old' LEADER and sought to achieve integration while recognising the challenges this presents, particularly across Axis 2.

The input from experienced personnel was undoubtedly instrumental in driving the process forward. The high degree of trust in particular individuals was essential to the process and owed more to personal attributes than institutional affiliations. This trust enabled capacity building and bridge-building in groups that was particularly valuable in developing mainstreaming mechanisms and for presenting opportunities for locally derived innovation. However, where trust was lacking this accentuated any imbalance between participants' perceptions of legitimacy and representativeness or their view of the appropriate application of expertise. The experience and knowledge of FD LAG made an important contribution to the development of the new programme but at the same time there was a perception among some respondents that FD LAG dominated the process, which was viewed in some quarters as 'stifling'. Scott (2004) cites the importance of capacity building and skills development for stakeholders to enable their effective participation in the partnership process, particularly for less experienced members. On the evidence of this study, this would be a useful intervention in Cumbria, particularly if itg was implemented by a trusted non-aligned source. This raises important questions about the nature of participation in programmes such as LEADER. As Rogers et al. (2008) note, the concept of increasing public participation in local policy and decision-making has only really gained prominence in the UK over the last ro years (Macnaghten and Jacobs I997; Burgess et al. I998; Smith et al. I999) and there is often a lack of understanding of what participation actually entails and what it is for (Michener I998; Hayward et al. 2004). A conscious choice of non-participation, or peripheral participation, can be as valid and empowering as the choice to participate actively (Hayward et al. 2004; Silver and Campbell 2005). Indeed, a study of sustainable community projects across the UK by Smith et al. (I999) also found that although the overall aim was to give communities a degree of real control over projects, community members were often reluctant to assume responsibility and looked to outside agencies for leadership. As a result, both the public and the organisations and authorities may be unsure as to how to move towards more community controlled projects.

It should be noted that elsewhere in Europe the tensions between competing driving forces on RDR delivery of simplification of structures, the strengthening of management, the integration of policies and the devolution of management result not only in a large variety of delivery structures giving different weights to these drivers but in changes in differing directions (Mantino et al. 2009). Thus, the 2007-2013 Plans in Greece and in Emilia-Romagna in Italy have seen recentralisation of powers delegated in the 2000-2007 plans because it appeared that re-centralisation seemed easier than strengthening capabilities at lower levels.

Nevertheless, despite the uncertainties in Cumbria, on balance it does seem that, given the wide consultation during the development of the SRIP, most of the respondents were reasonably happy with the level of engagement and participation in the process. This must represent a general endorsement, even if, at times, and for some potential LAG interests, it has been a pragmatic endorsement.

The RDR allows, through flexibility in the percentages of funding to Axes I-3, a national view to emerge and in the RDPE, the government has highlighted the 
importance of the environment by allocating the maximum percentage of funds to Axis 2. The issue of measure selection was a major concern for respondents. In order to achieve the most effective use of LEADER funds in Cumbria, and in order to produce the best possible integration with other policies funds and objectives, it may be necessary to take a highly flexible approach to the allocation of funds on the ground and to allow the opportunity to move between measures as the LAGs develop their local strategies. Furthermore, at the regional level, while there is a need for a strategic fit across various programmes, in the course of a 6-year programme it will be important to constantly review and update the strategic fit as new external policies develop. This is likely to present significant challenges, not least in terms of balancing bottom-up approaches with top-down programme aims, as delivered through a mainstreamed LEADER approach.

These issues have parallels throughout Europe where there has been 'a flowering of integrated and partnership approaches ... despite ... perplexity over the real will of the Regions to support them ... or the capacity for administrative technical back-up' (Mantino 2009, p. I6).

In Cumbria the difficulties concerning LAG geography were also exacerbated by a need (perceived or otherwise) to fulfil requirements of the EU as interpreted by the NWDA. This may have stifled the participants' ability to form a more diverse LAG structure and prevented them from separating the EBS LAG into more appropriate, manageable geographical areas.

The issue of integration raises a number of broader themes: the scope for truly innovative project development outside projects such as tourism and farm produce; and the need to examine national, regional and global drivers and influences. Conversely, the need to examine and integrate the effects of project developments in Cumbria on the region, and on national environmental issues must be recognised, especially in terms of their environmental impact on rural dwellers. Again, we refer to Folke et al. (2005, p. 44I) and their theory of adaptive management. As discussed earlier, the present LAG structure in Cumbria is expert-orientated. We argue that there is a pressing need to develop alternative sets of pathways across the LAGs through which integration could occur, linking together individuals, organisations, agencies, and institutions at multiple levels. The LAGs would necessarily draw on a range of knowledge systems and experiences for what Folke calls the development of common understanding and policies. These are issues that the LAGs must consider if they are to develop truly integrated and innovative rural development projects. However, integration is not an end in itself, but is a precursor to the development of a policy system that can deliver sustainable environments, communities and economies. Integration must therefore be seen as a fundamental part of strategic planning, both for the LAG groups and the agencies delivering Axis 2. This will necessarily involve developing new and innovative ways of working but it is the logical way of combining a sub-regional devolved partnership approach (on all axes of the RDR) with regional-level integration of Axes I and 3 by the NWDA and of these with Axis 2 by Natural England. The separation of Axis 2 is an unusual delivery structure in the EU and Natural England is centralist in its approach to policy. Nevertheless, it is a participant in both the Cumbria LAG and regional processes. 
The new RDR thus provides the opportunity for LAGs to be at the heart of all rural development measures and to play an important role in tailoring projects to meet the local situation. Indeed, the previous LEADER programmes in Cumbria were successful largely because they did precisely that. We argue that the approach taken by the NWDA in mainstreaming LEADER in Cumbria hinders rather than helps this process. An over-complicated management structure and an apparent reluctance to devolve responsibility have led to significant delays in project funding and have damaged the credibility of the LEADER brand in Cumbria. We have been critical of the NWDA, but the inherent tensions, widely anticipated throughout the EU (Rural Development Impacts 20IO) between mainstreaming and an approach (LEADER) that was largely developed to be small, local and participatory, must be recognised. This is not to say that mainstreaming LEADER is impossible but rather that a more thoughtful, local and devolved approach than that provided by the NWDA is required.

\section{Notes}

* Corresponding author.

I The NWDA is one of nine regional development agencies in England and was set up by the government in I999. All regional development agencies are government-sponsored public bodies and are tasked with leading the economic development and regeneration of England's regions.

2 The Government Office for the North West works with organisations across the region to deliver government policies and programmes.

3 Natural England is the government's advisor on the natural environment. Their responsibilities include managing England's environmental and green farming schemes, designating national parks and areas of outstanding natural beauty, notifying sites of special scientific interest and managing the government's obligations to international biodiversity agreements, including the licensing of protected species across England.

4 The Forestry Commission is the government department responsible for the protection and expansion of Britain's forests and woodlands. Founded in I9I9, it is the largest land manager in Britain with an estate covering some 258,000 ha.

5 The former European Agriculture Guidance and Guarantee Fund has effectively been split into the European Agricultural Guarantee Fund (Pillar I, for area payments based on market and price support policies) and the European Agricultural Fund for Rural Development (Pillar II, for rural development policies, which also includes the agri-environment component). The rules governing EU rural development policy for the period 2007-2013 are set out in Council Regulation (EC) no. $1698 / 2005$.

6 The RDPE 2007-2013 has a budget of $£ 3.9$ billion nationally, of which approximately $£ 400$ million is allocated to the north-west (of which the NWDA is responsible for $£ 74.92$ million).

\section{References}

Austrian Institute for Regional Studies and Spatial Planning (2004) Methods for and success of mainstreaming leader innovations and approach into rural development programmes. Final report commissioned by European Commission, DG Agriculture, Unit G4. Available online at http://ec.europa.eu/agriculture/eval/reports/leader/index_en.htm Accessed 20 November 2008 
Barke, M. and M. Newton (I997) The EU LEADER initiative and endogenous rural development: the application of the programme in two rural areas of Andalusia, southern Spain. Journal of Rural Studies I3 (3) pp. 3I9-34I

Bruckmeier, K. (2000) LEADER in Germany and the discourse of autonomous regional development. Sociologia Ruralis 40 (2) pp. 219-227

Bryden, J. (2006) Special focus: from LEADER I to LEADER+ and beyond to the LEADER Axis. LEADER+ Magazine. 6, pp. 8-I4

Buller, H. (2000) The French experience with LEADER. Sociologia Ruralis 40 (2) pp. I90-I99

Burdett, A. (2008) Rural Cumbria has been starved of cash by political wrangles. The Cumberland News, Friday, I8 July. Available online at http://www.cumberland-news.co.uk/farming/ rural_cumbria_has_been_starved_of_cash_by_political_wrangles_I_205979? referrerPath= home/cn_search_results_2_3080 Accessed 24 May 2010

Burdett, A. (2009) Cumbrian farmers still waiting for cash from $£_{\mathrm{I}} \mathrm{G}$ million grants pot. The Cumberland News, Friday, I5 May. Available online at http://www.cumberland-news.co. uk/news/cumbrian_farmers_still_waiting_for_cash_from_I6_million_grants_pot_I_ 555039?referrerPath=home/cn_search_results_2_3080 Accessed 24 May 2010

Burgess, J., C.M. Harrison and P. Filius (1998) Environmental communication and the cultural politics of environmental citizenship. Environment and Planning A 30 (8) pp. I445-I460

Cazorla-Montero, A., I. de los Rios-Carmenado and J.M. Diaz-Puente (2005) The LEADER community initiative as rural development model: application in the capital region of Spain. Agrociencia 39 (6) pp. 697-708

Courades, J.M. (2004) LEADER Axis - rural development policy 2007-2013. Available from: http://www.agro-info.org.pl/files/index.php?id_plik=I027 Accessed: 2I December 2009

Cumbria Sub-regional Implementation Plan (SRIP) (2007) Rural development programme for England (RDPE). Available online at http://www.nwda.co.uk/docs/Cumbria_I5oct2007.doc Accessed 26 October 2008

Darker, C.D., M. Larkin and D.P. French (2007) An exploration of walking behaviour - an interpretative phenomenological approach. Social Science and Medicine $6_{5}$ (Io) pp. 2I72-2I83

Department of Environment, Food and Rural Affairs (DEFRA) (2009) Leader maps. Available online at http://www.defra.gov.uk/rural/rdpe/leader-maps/index.htm Accessed 5 January 2010

Folke, C., T. Hahn, P. Olsson and J. Norberg (2005) Adaptive governance of social-ecological systems. Annual Review of Environment and Resources 30 pp. 44I-473

Forest Research (2005) Small is beautiful: forest futures. Available online at http://www. forestresearch.gov.uk/pdf/nwe-small-is-beautiful.pdf/\$FILE/nwe-small-is-beautiful.pdf Accessed 20 November 2008

Hayward, C., L. Simpson and L. Wood (2004) Still left out in the cold: problematising participatory research and development. Sociologia Ruralis 44 (I) pp. 95-108

Jordan, A.L., C. Eccleston and M. Osborn (2007) Being a parent of the adolescent with complex chronic pain: An interpretative phenomenological analysis. European Journal of Pain II (I) pp. $49-56$

McEvoy, D., K. Lonsdale and P. Matczak (2008) Adaptation and mainstreaming of EU climate change policy: an actor-based perspective Policy brief no. I4 (Brussels: Centre for European Policy Studies, 9).

MacKinnon, D. (2002) Rural governance and local involvement: assessing state - community relations in the Scottish Highlands. Journal of Rural Studies I8 (3) pp. 307-324

Macnaghten, P. and M. Jacobs (I997) Public identification with sustainable development: investigating cultural barriers to participation. Global Environmental Change 7 (I) pp. 524

Mantino, F. (2009) Assessing the impact of rural development models (including LEADER) typologies of governance models, FP 7 Project no. 213034. Funded by the 7 th Framework Programme for Research and Technology Development of the European Commission. 
Available online at http://www.rudi-europe.net/uploads/media/RuDI_WP3_D_3.2.pdf Accessed 22 March 2010

Mantino, F., M. Bolli, M. Fagiani and S. Tarangioli (2009) Report on policy delivery systems and their relations with types of governance. Assessing the impact of rural development models (including LEADER). Available online at http://www.rudi-europe.net/uploads/media/ RuDI_WP3_D_3-3.pdf Accessed 22 March 20I0

Michener, V.J. (1998) The participatory approach: contradiction and co-option in Burkina Faso. World Development 26 (I2) pp. 2105-2II8

North West Development Agency (NWDA) (2007) Rural development programme for England: the implementation plan for England's Northwest 2007-2013. Available online at http://www.nwda.co.uk/pdf/Draft\%20RDPE\%20NW\%20Implem\%2oPlan.pdf Accessed 27 October 2008

Olsson, P. and C. Folke (2004) Adaptive comanagement for building resilience in socialecological systems. Environmental Management 34 (I) pp. 75-90

Olsson, P., L.H. Gunderson, S. Carpenter, R. Ryan, L. Lebel, C. Folke and C.S. Holling (2006) Shooting the rapids: navigating transitions to adaptive governance of socio-ecological systems. Ecology and Society II (I) pp. I-I8

Ostrom, E. (2005) Understanding institutional diversity (Princeton, NJ: Princeton University Press)

Perez, J.E. (2000) The LEADER programme and the rise of rural development in Spain. Sociologia Ruralis 40 (2) pp. $20 \mathrm{I}-207$

Ray, C. (2000) The EU LEADER programme: rural development laboratory. Sociologia Ruralis 40 (2) pp. I63-I7I

Reid, K., P. Flowers and M. Larkin (2005) Exploring lived experience. The Psychologist I8 (I) pp. 20-23

Rogers, J., I. Convery, E. Simmons and A. Weatherall (2008) Public perceptions of communitybased renewable energy projects. Energy Policy 36 (II) pp. 42I7-4226

Rural Development Impacts (20I0) 7th framework research programme Rudi Europe. Available online at: http://www.rudi-europe.net/ Accessed 22 March 2010

RDPE (2007) The rural development programme for England 2007-2013. Available online at: http://www.defra.gov.uk/rural/rdpe/ Accessed 24 May 2010

Scott, M. (2002) Delivering integrated rural development: insights from Northern Ireland. European Planning Studies Io (8) pp. IOI3-I025

Scott, M. (2004) Building institutional capacity in rural Northern Ireland: the role of partnership governance in the LEADER II programme. Journal of Rural Studies 20 (I) pp. 49-59

Silver, J.J. and L.M. Campbell (2005) Fisher participation in research: dilemmas with the use of fisher knowledge. Ocean and Coastal Management 48 (9-10) pp. 72I-74I

Smith, J.A. (2004) Reflecting on the development of interpretative phenomenological analysis and its contribution to qualitative research in psychology. Qualitative Research in Psychology I (I) pp. 39-54

Smith, J.A. and M. Osborne (2003) Interpretative phenomenological analysis. Pp. 53-80 in J.A. Smith, ed. Qualitative psychology: a practical guide to research methods (London: Sage)

Smith, J., J. Blake, R. Grove-White, E. Kashefi, S. Madden and S. Percy (I999) Social learning and sustainable communities: an interim assessment of research into sustainable communities projects in the UK. Local Environment 4 (2) pp. I95-207

Solway, Border and Eden Local Action Group (SBE LAG) (2008) Local development strategy. Available online at: http://www.nuleader.eu/neighbouringleaderareas.htm Accessed 25 May 2010

Storey, D. (I999) Issues of integration, participation and empowerment in rural development: the case of LEADER in the Republic of Ireland. Journal of Rural Studies I5 (3) pp. 307-3I5

Tomura, M. (2009) A prostitute's lived experiences of stigma. Journal of Phenomenological Psychology 40 (I) pp. 5I-84 
Vidal, R.V.V. (2009) Rural development within the EU LEADER+ programme: new tools and techniques. AI and Society 23 (4) pp. 575-602

Woods, M. (2005) Rural geography (London: Sage)

lan Convery*
Faculty of Science and Natural Resources
University of Cumbria
Newton Rigg
Penrith, CA 11 oAH UK
e-mail: ian.convery@cumbria.ac.uk
lan Soane
University of Cumbria
Newton Rigg
Penrith, CA 11 oAH UK

Tom Dutson

Faculty of Science and Natural Resources

University of Cumbria

Newton Rigg

Penrith, CA11 OAH UK

Helen Shaw

Faculty of Science and Natural Resources

University of Cumbria

Newton Rigg

Penrith, CA11 OAH UK 